\title{
STRUCTURAL PATTERNS IN THE CONSTRUCTION OF THE QURANIC SCENE، A READING IN THE PURPOSES OF SHARIA
}

\author{
Basim Rashid ZOBAA ${ }^{1}$ \\ Osama Hamdan Abdullah RAHIM ${ }^{2}$
}

\section{Istanbul / Türkiye \\ p. $656-669$}

\begin{abstract}
Received: $24 / 11 / 2021$
Accepted: 09/12/2021

Published: 01/01/2022
\end{abstract}

This article has been scanned I iThenticat No plagiarism detected

\begin{abstract}
:
The Holy Qur'an is the Book of God Almighty، and He described it، Glory be to Him, with several descriptions, and He told about it that it is a book that needs contemplation that leads you to the goal of the intended verses, and you think about the verses، rather the wall، to come up with a conception of it. The event, rather, depicts it from its different angles, and that is the camera in the Holy Qur'an, as it paints for us a vivid scene that pulsates with life in which all the meanings of life are dialogues and embodiment of what is not in a body, a chemical substance or a physical space. The place is separate from the time, but the study of the scene is fragmented, with a metaphor here or a metaphor there, this kills the scene and takes it out of its beauty.

For this reason, the choice was made to study the scene in the Holy Qur'an، in order to clarify the beauty of the Holy Qur'an that is not limited to the verbal only, but comes out in the word to what is embodied، reasonable and metaphysical.

This research is based on an introduction in which I talked about the scene in language and terminology, then she added to talk about the role of some linguists in approximating the term scene. As for the requirements of the research, the first of them is devoted to the study of material examples, as the importance of the material aspect in nature in general is mentioned in it, and this is supported by texts from the Noble Qur'an.

As for the second، it was to study the moral examples، so I talked about the abstract morals, which are the perceptions of the mind, which do not possess tangible or tangible entities, and I included them with some examples of what was mentioned in the Holy Qur'an as well.

As for the third, it was to study the unseen examples, in which I dealt with talking about the unseen, which is everything that is absent from man, corroborating that with what was mentioned in the Holy Qur'an.

Finally, I say: This is a humble work in its chapter whose goal is to serve the word of God Almighty.
\end{abstract}

Key words: Construction, Research, Study.

http://dx.doi.org/10.47832/2717-8293.15.45

(iD) Prof. Dr., AL- Iraqia University, Iraq, b866198@gmail.com

2 (iD) Dr. , Sunni Endowment Diwan, Iraq

Copyright (C) Published by Rimak Journal, www.rimakjournal.com Rimar Academy, Fatih, Istanbul, 34093 Turkey 


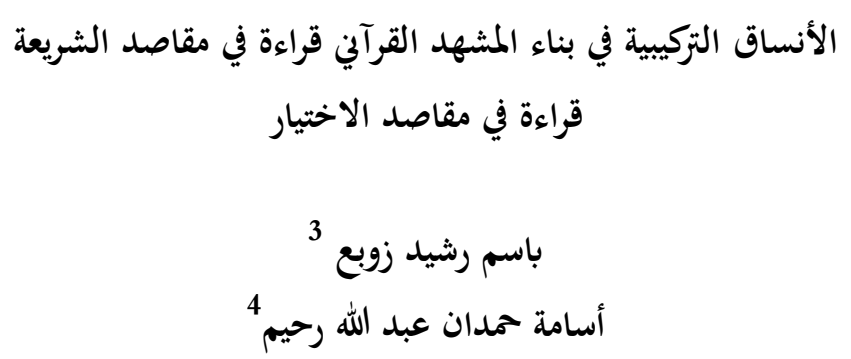

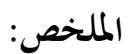

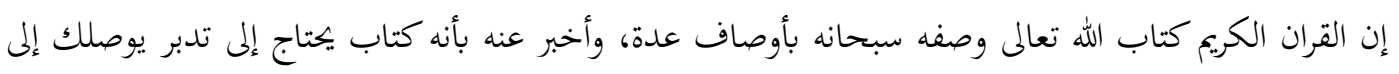

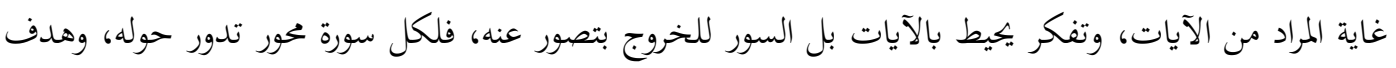

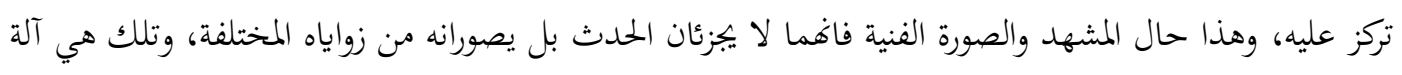

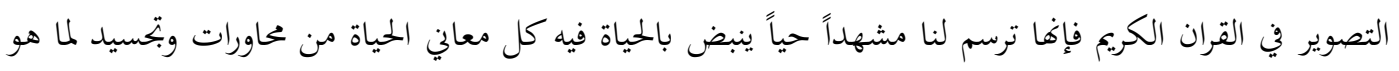

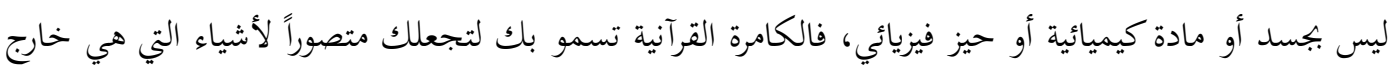

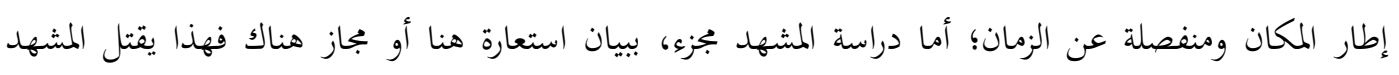

$$
\text { ويخرجه من جماليته. }
$$

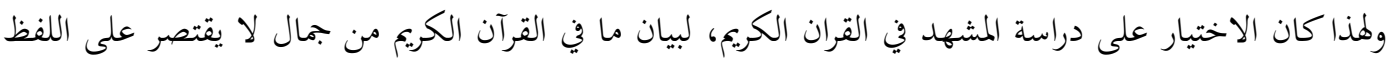

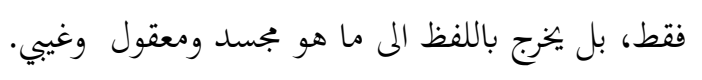

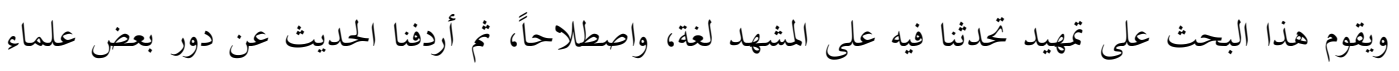

$$
\text { اللغة في تقريب مصطلح المشهد. }
$$

أما مطالب البحث، فقد أفردنا الأول منها لدراسة الأمثلة المادية، إذ ذكرنا فيه أهمية الجانب المادي في الطبيعة

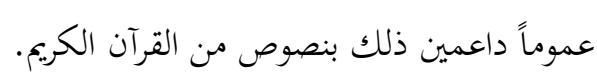

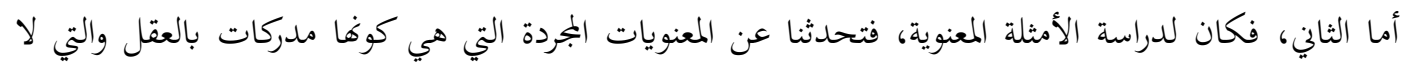

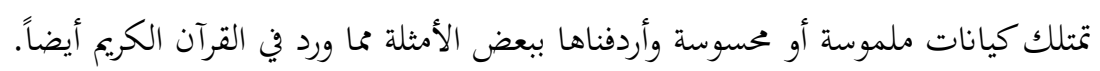

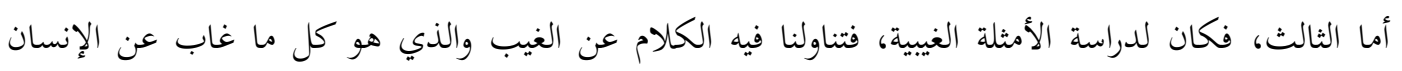
معضدين ذلك بما ورد منه في القرآن الكريم. وأخيرا نقول: هذا عمل متواضع في بابه غايته خدمة كلام الله تعالى، فإن كان قاصراً فمن نفسينا والشيطان، وإن كان تاماً فبتوفيق منه سبحانه. الكلمات المفتاحية: القران الكريم، الأنساق التركيبة. 
إن القران الكريم كتاب الله تعالى وصفه سبحانه بأوصاف عدة، وأخبر عنه بأنه كتاب يحتاج إلى تدبر يوصلك إلى غاية

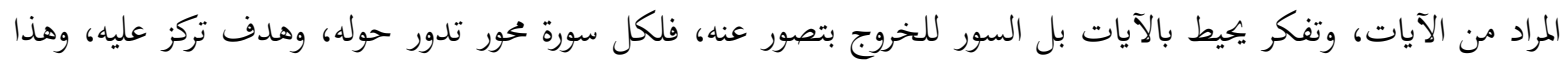

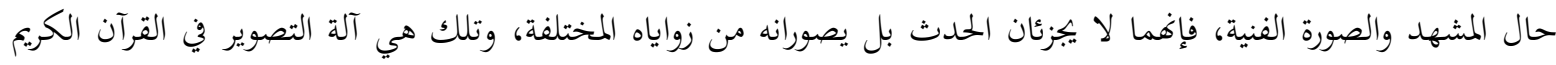

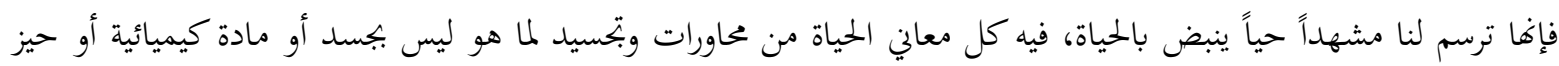

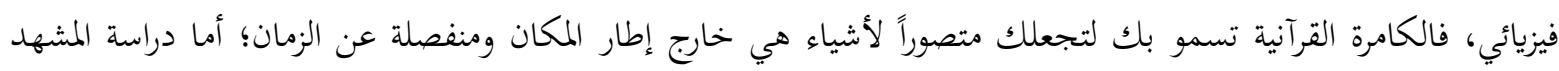

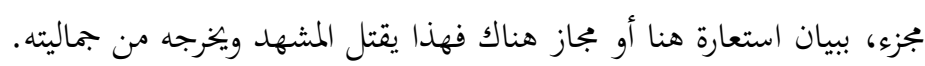

ولهذا كان الاختيار على دراسة المشهد في القرآن الكريم، لبيان ما في القرآن الكريم من جمال لا يقتصر على اللفظ فقط بل يخزج باللفظ إلى ما هو مجسد ومعقول وغيبي.

ويقوم هذا البحث على تمهيد تحدثت فيه على المشهد لغة، واصطلاحاً، ثم أردفت الحديث عن دور بعض علماء اللغة في تقريب مصطلح المشهد.

وقسمت البحث إلى ثلاثة مباحث تبعاً لمتطلباته، فقد أفردت الأول منها لدراسة الأمثلة المادية. أما الثاني، فكان لدراسة الأمثلة المعنوية. والثالث، فكان لدراسة الأمثلة الغيبية. وأخيراً أقول: هذا عمل متواضع في بابه غايته خدمة كلام الله تعالى، فإن كان قاصراً فمن نفسي والشيطان، وإن كان تاماً فبتوفيق منه سبحانه.

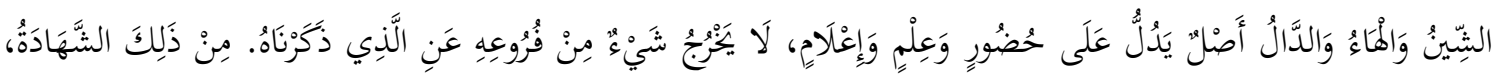

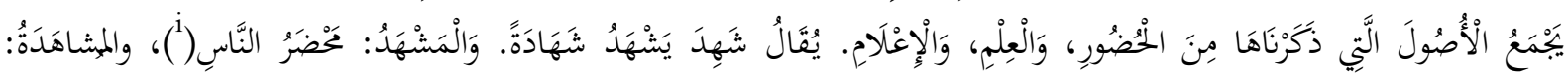

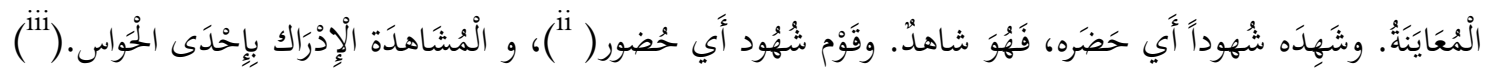

هو إخراج مدلول اللفظ من دائرة المعنى الذهني المجرد إلى الصورة المحسوسة المتخيلة، والحادث المحسوس، والمشهد المنظور، والنموذج الإنساني والطبيعة البشرية، ثم يرتقي بالمشهد الذي يصوره فيمنحه الحياة الشاخصة، أو الحركة المتجددة. فإذا المعنى الذهني هيئة أو حركة، وإذا الحالة النفسية لوحة أو مشهد، وإذا النموذج الإنساني شاخص حي، وإذا الطبيعة

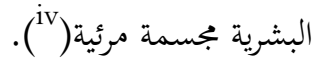

\section{دور علماء اللغة في تقريب مصطلح المشهد القرآني :}

لقد التفت علماء البلاغة واللغة القدماء إلى ظاهرة المشهد والصورة الفنية وإن لم يسموها باصطلاحنا المعاصر، وقد أشار في

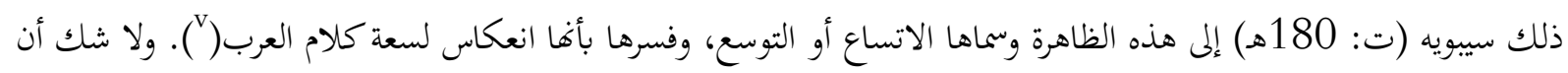

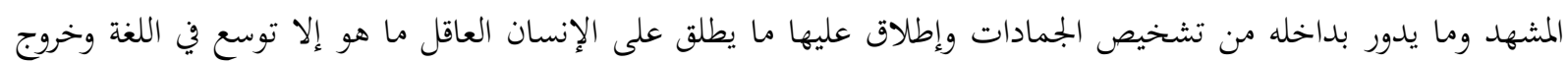

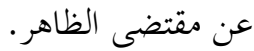


وأشار أبو عبيدة إلى هذه الظاهرة الأدبية وسماها: (بجاز ما جاء من لفظ خبر الحيوان والموات، على لفظ خبر

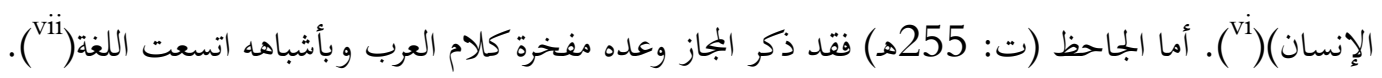
وتحدث ابن المعتز عن هذه الظاهرة بشيء من الوضوح عند حديثه عن شعر امرئ القيس:

\section{وليل كموج البحر أرخى سدوله عليَّ بأنواع المموم ليبتلي

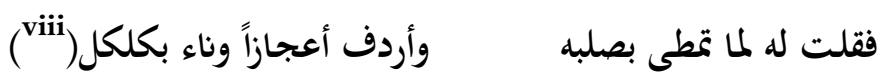

هذا كله من الاستعارات؛ لأن الليل لا صلب له ولا عجز( (ix)، وكان ابن المعتز يريد أن يقول إن امرأ القيس قد خلع على

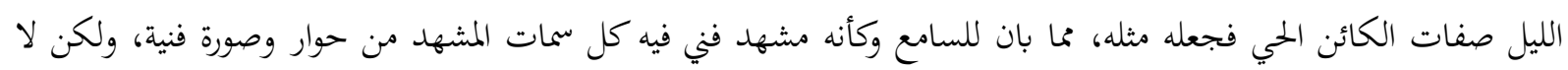

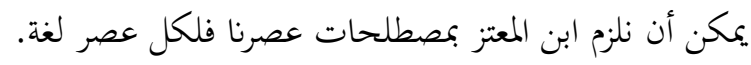

أما عبد القاهر الجرجاني (ت: 471هـ) فقد تناول موضوع الصورة الفنية، ويعد أدق من وقع على معنى المشهد وما يدور

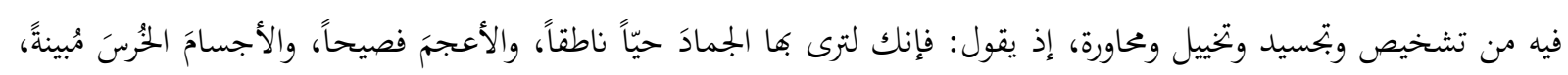

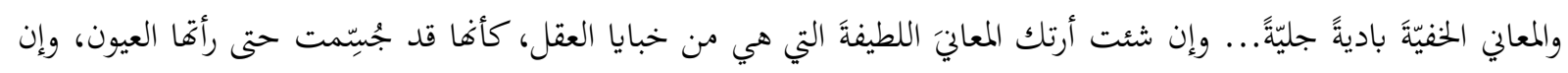

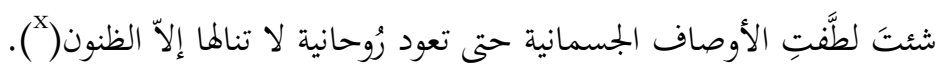
ويعلق الجرجاني على قول لبيد:

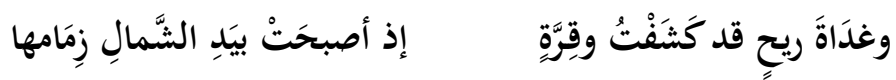

وذلك أنه جعل للشمال يداً، ومعلوم أنه ليس هناك مُشار إليه يمكن أن ثُجْرَى اليد عليه، كإجراء الأسد والسيف على لى

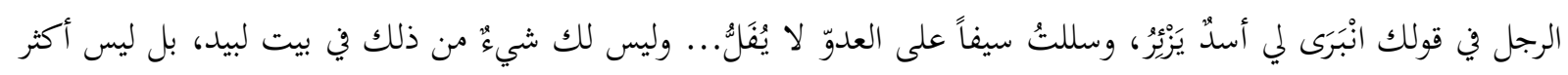

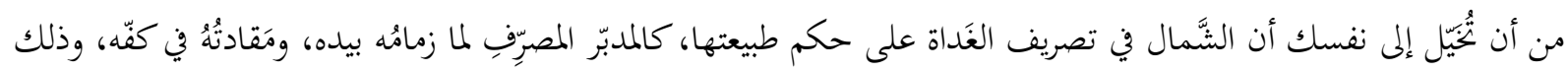

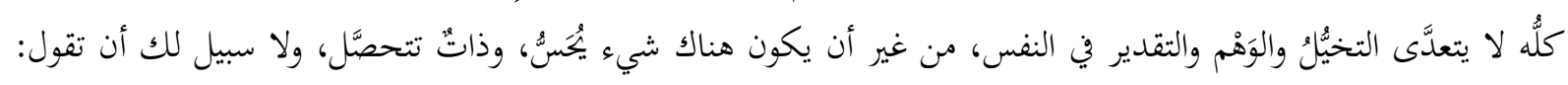

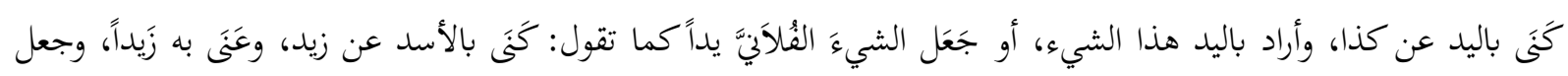

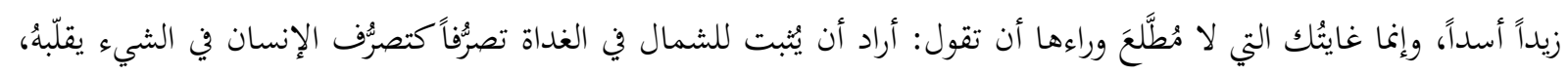

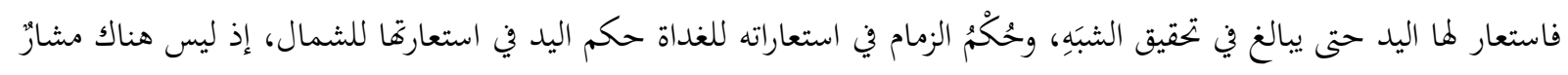

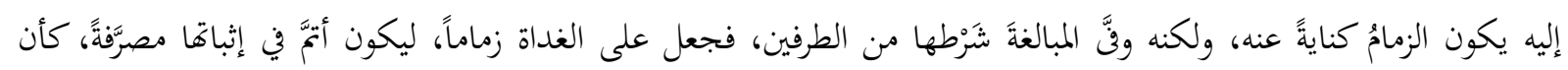

جعل للشمال يداً، ليكون أبلغ في تصييرها مُصرَّفِة(

وفي ضوء ما تقدم نستطيع أن نقول: إن علماءنا تنبهوا إلى هذه الخاصية الأسلوبية وأحسوا بوجودها وعرفوا مفهومها دون

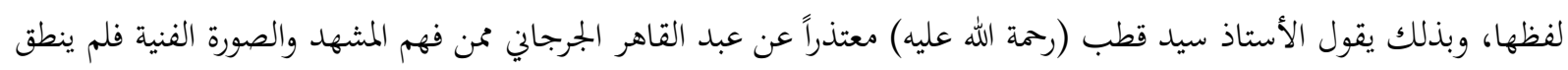

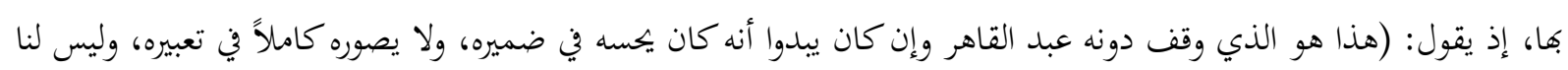

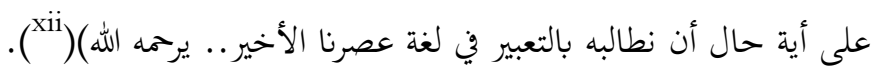




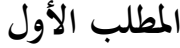 \\ النسق التركيب للمشاهد الملموسة}

يعد الجانب المادي من الطبيعة عموماً من أبرز مظاهرها المحسوسة التي تشكل حيزاً وجودياً ملموساً، فضلاً عن كون الطبيعة

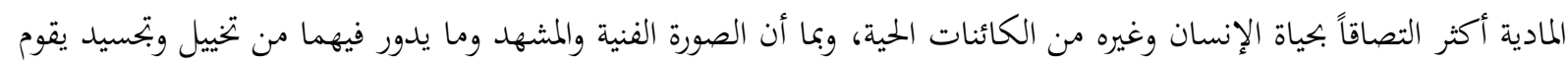

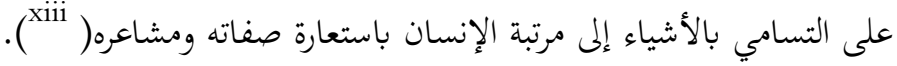

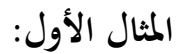

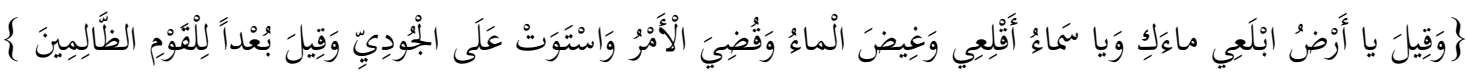

$$
\text { [44 سورة هود: آية }
$$

منح المشهد القرآي بما فيه من تشخيص وبحسيد الأرض والسماء بعداً إنسانياً، فقد خصهما الله تعالى بالخطاب، ووجه

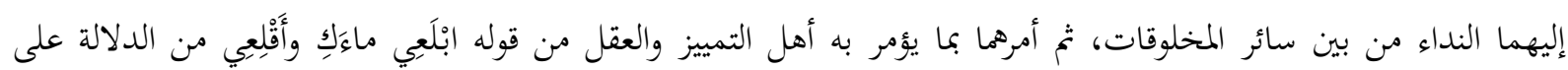

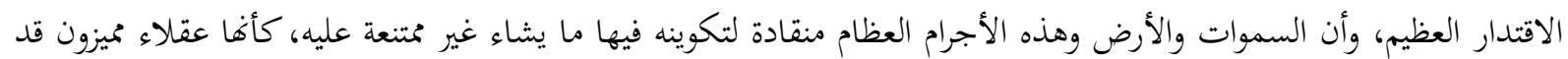

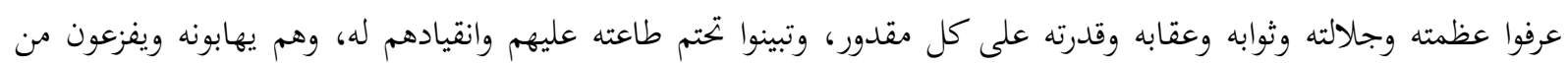

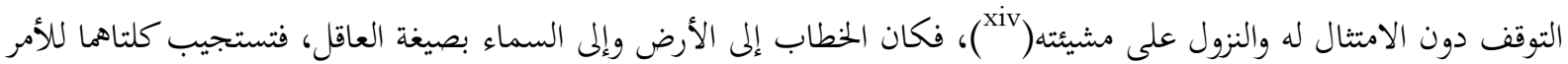

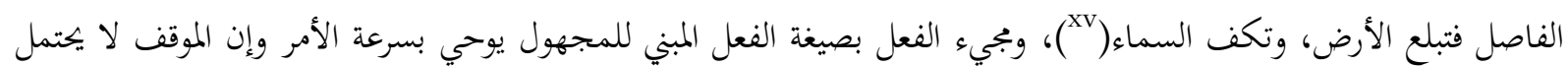

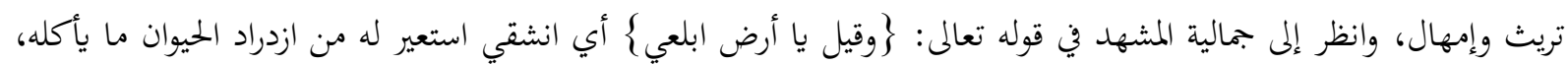

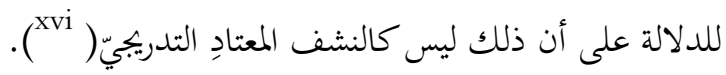

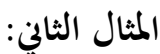

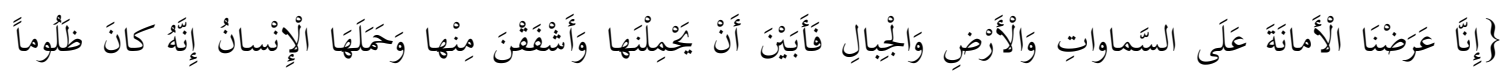
جَهُولاًا\{ [سورة الأحزاب: آية

إن بداية الآية أو مشهد العرض يوحي بتجسيم الأمانة حملاً ثقيلاً وعبئًا كبيراً يرزح تحت وطأته من يكلف بحمله ما استدعى بروز صفات إنسانية معنوية شعورية في هذه الجمادات التي انبرت تدفع عن نفسها هذا الحمل الثقيل.... أما في في قوله

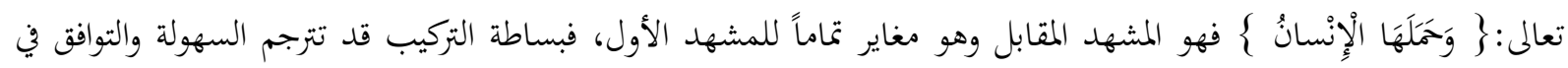
تقبل الأمر دون تفكير في العواقب $\}$ إِنَّهُ كانَ ظَلْوماً جَهُولًا

إن هذا المشهد، فيه إيقاع يكشف عن جسامة العبء الملقى على عاتق البشرية، وعلى عاتق الجماعة المسلمة بصفة خاصة

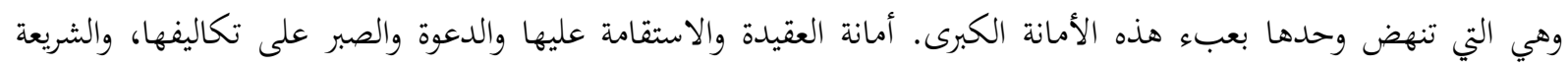

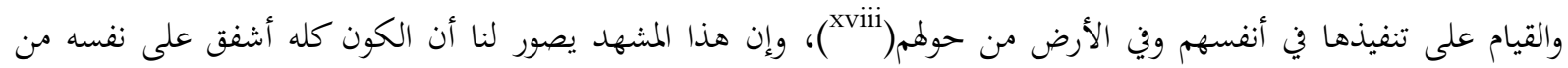

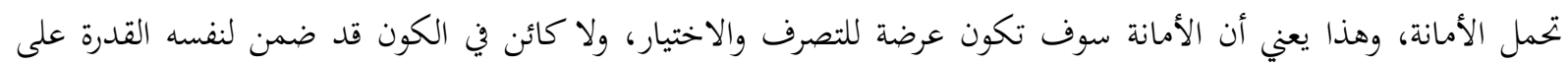

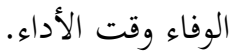

لقد أعلنت الكائنات قولها فأبين تحمُّل الأمانة وكأها قالت: إنّا يا ربنا نريد أن نكون مسخرين مقهورين لا اختيار لنا؛ ولذلك نجد الكون كله يؤدي مهمته كما أرادها الله تعالى، ما عدا الإنسان، أي أنه الذي قبل بما له من عقل وتفكير أن يتحمل أمانة الاختيار، وبلسان حاله أو بلسان مقاله قال: إنني قادر على تحمل الأمانة؛ لأني أستطيع الاختيار بين البدائل( 


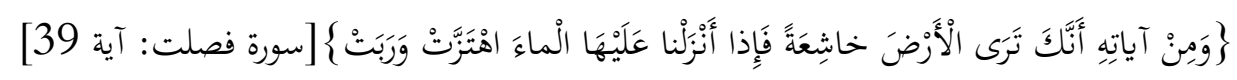

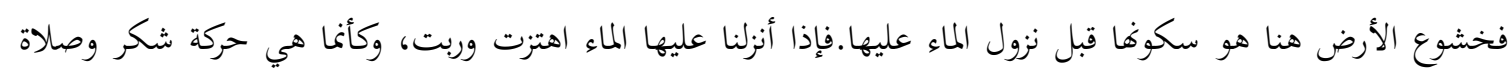

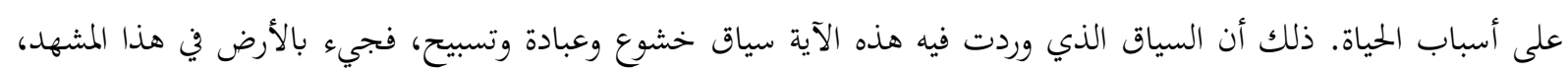

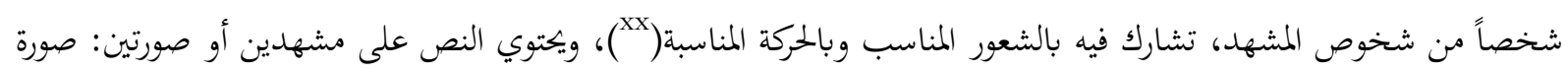

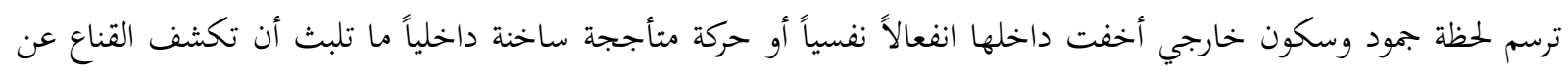

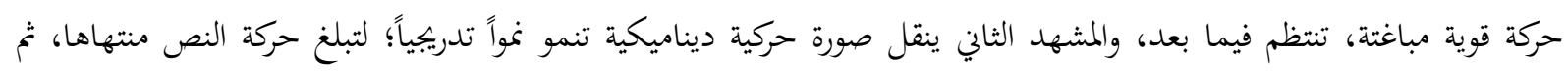

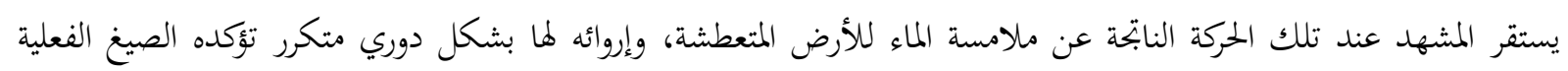

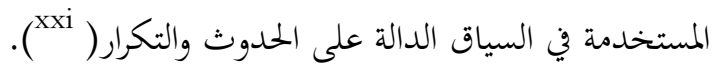


المعنويات المجردة هي المدركات بالعقل، التي لا تملك كياناً مادياً ملموساً أو محسوساً، لكنها تعد الوجه الآخر للوجود،

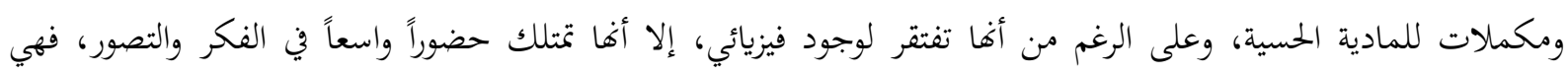

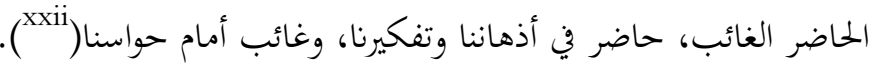

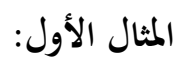

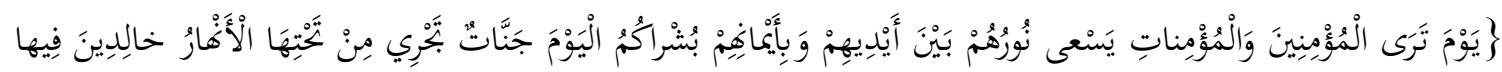

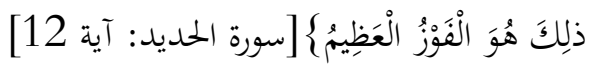

والمشهد هنا بإجماله وتفصيله جديد- بين المشاهد القرآنية- وهو من المشاهد التي يحييها الحوار بعد أن ترسم صورتا

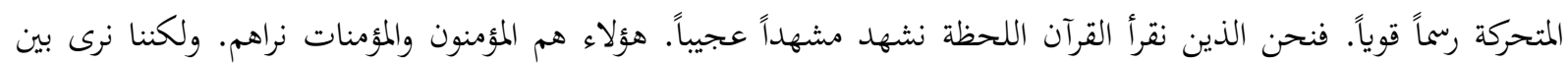

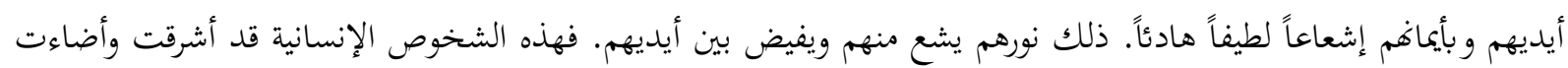
وأشعت نوراً يمتد منها فيرى أمامها ويرى عن يمينها.

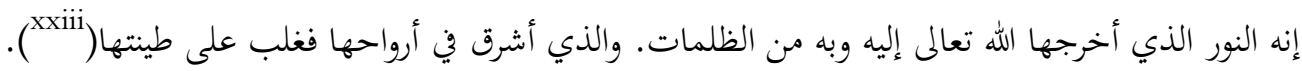
المثال الثاني:

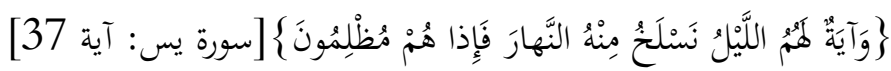
سلخ جلد الشاة: إذا كشطه عنها وأزاله...فاستعير لإزالة الضوء وكشفه عن مكان الليل وملقى ظله( (xxiv)، وأشار أبو هلال العسكري إلى معنى السلخ في هذه الآية، وهو أن الليل والنهار ليسا على الحقيقة شيئين يسلخ أحدهما من الآخر، إلا أفما

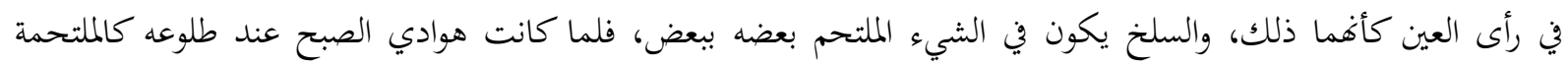

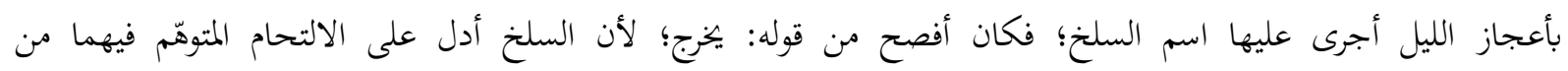

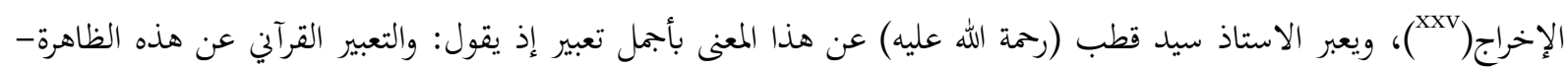

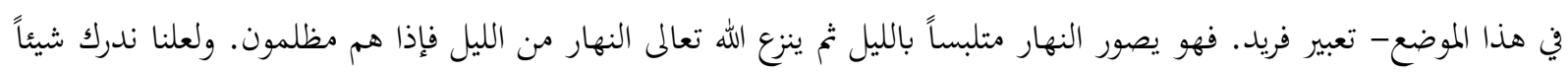
من سر هذا التعبير الفريد حين نتصور الأمر على حقيقته. فالأرض الكروية في دورتحا حول نفسها في مواجهة الشمس تمر كل نقطة منها بالشمس فإذا هذه النقطة فار حتى إذا

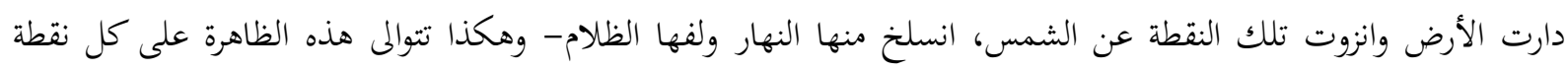
بانتظام وكأنما نور النهار ينزع أو يسلخ فيحل محله الظلام. فهو تعبير مصور للحقيقة الكونية أدق تصوير(

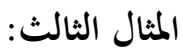

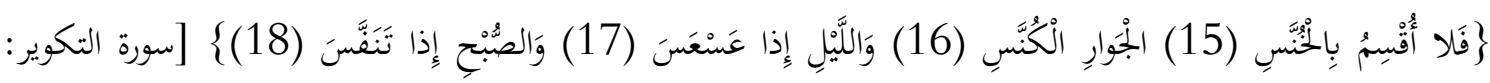

الآيات 15 الى 18

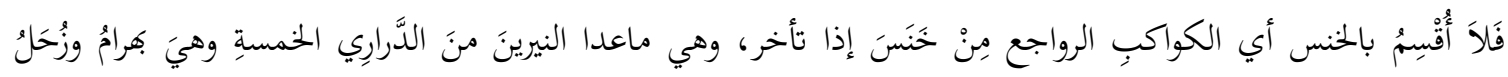

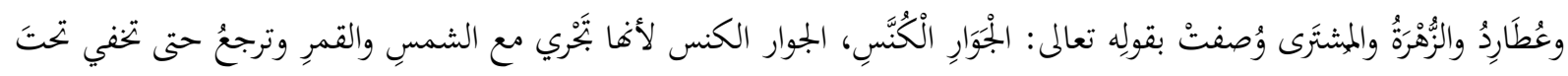

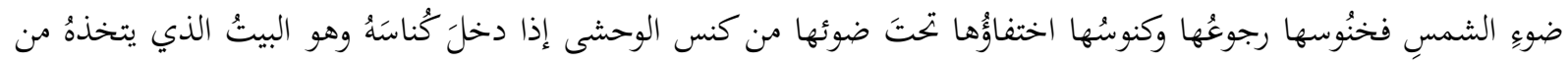




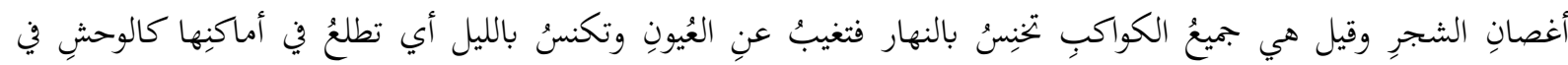

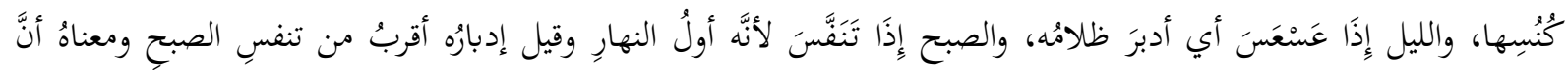

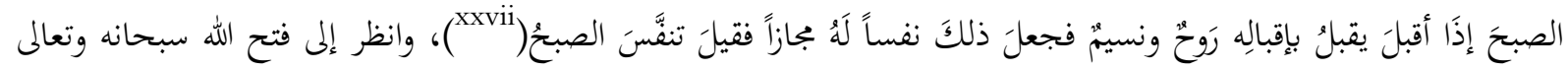

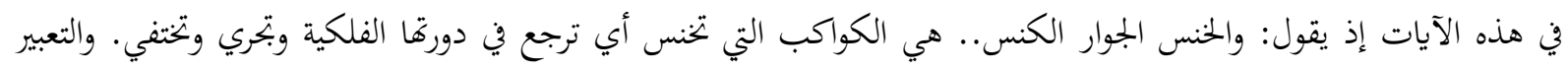

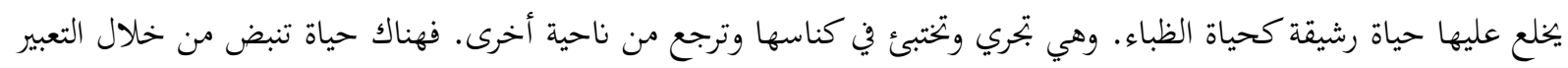

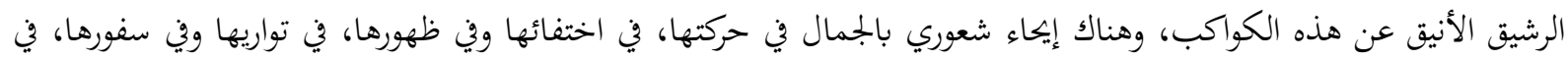

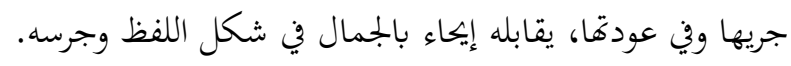

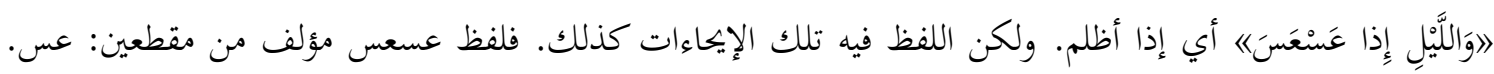

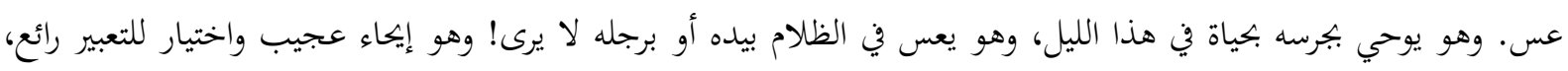

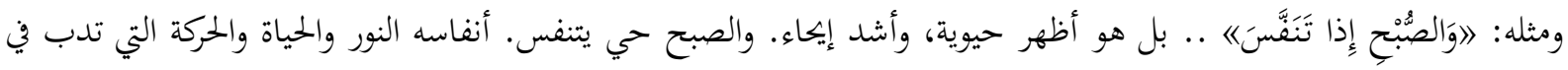

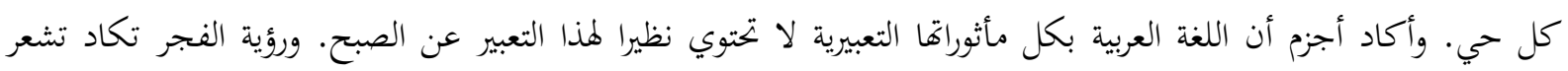
القلب المتفتح أنه بالفعل يتنفس! ثم يجيء هذا التعبير فيصور هذه الحقيقة التي يشعر بها القلب المتفتح.

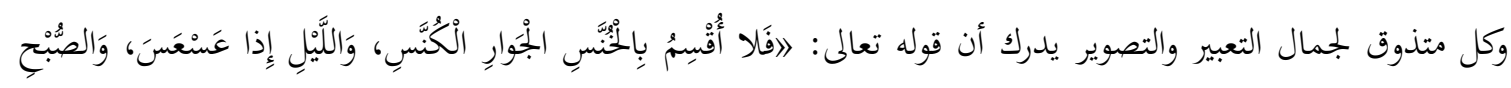

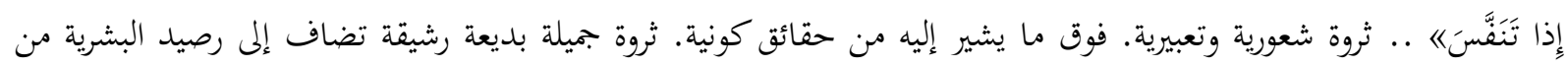
المشاعر، وهي تستقبل هذه الظواهر الكونية بالحس الشاعر. يلوح هذه المشاهد الكونية التي يخلع عليها الحياة ويصل روح الإنسان بأرواحها من خلال التعبير الحي الجميل عنها

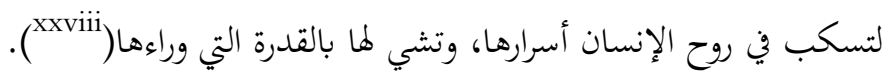

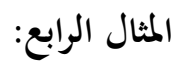

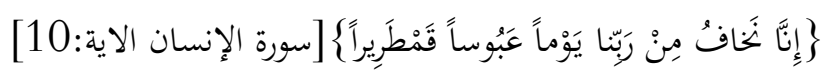

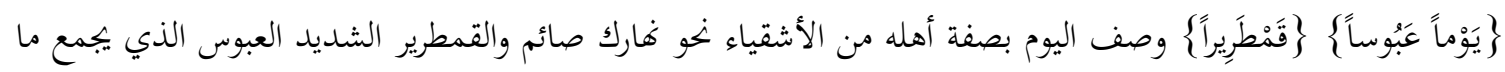

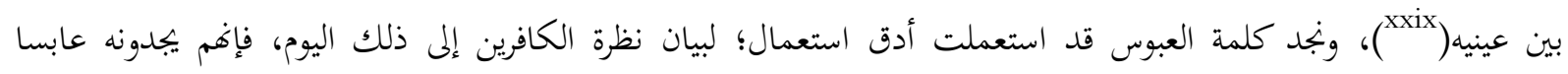

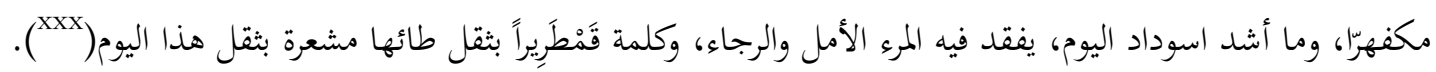
إن الخوف الشديد الذي يعتمل القلوب من هول ذلك اليوم، والإحساس الداخلي بخطورة الموقف في الزمن القادم جعل

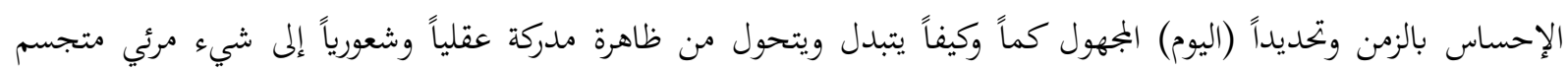

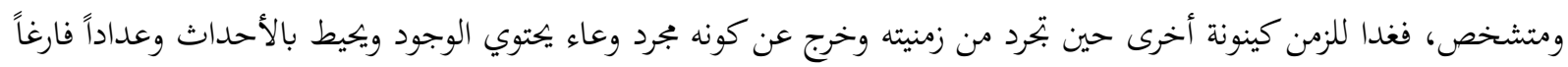

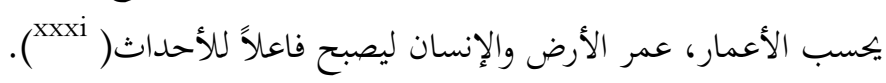




\section{النسق التركيبي لمشاهد المآلات الغيبية}

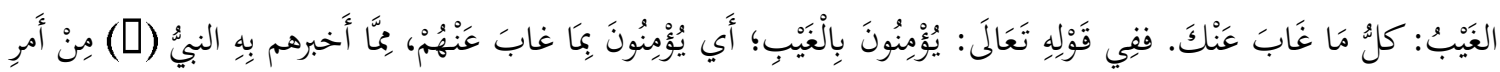

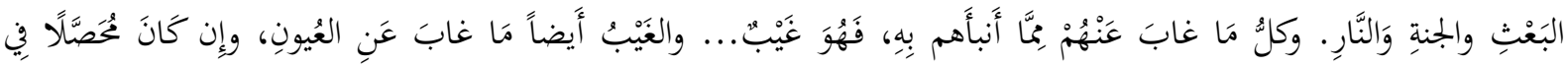

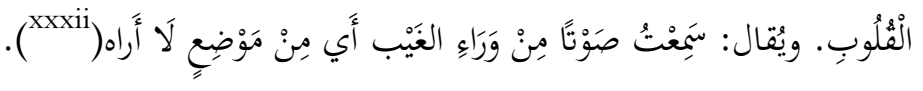

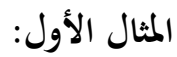

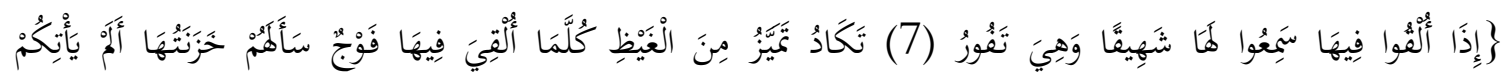

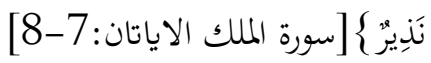

المنكر الفظيع بالشهيق وَهِيَ تَفُورُ تغلى بهم غليان المرجل بما فيه. وجعلت كالمغتاظة عليهم لشدة غلياها بهم، ويقولون: فلان يتميز غيظاً ويتقصف غضباً، وغضب فطارت منه شقة في الأرض وشقة في السماء: إذا وصفوه بالإفراط فيه(

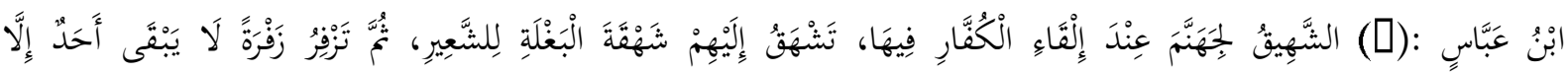

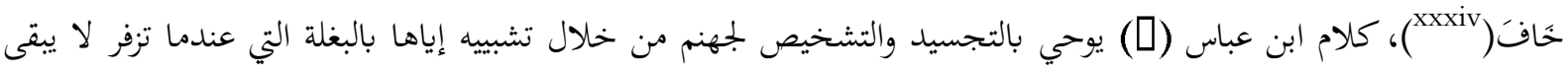

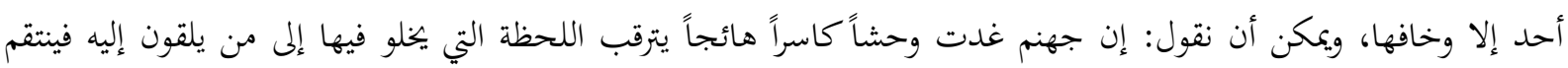

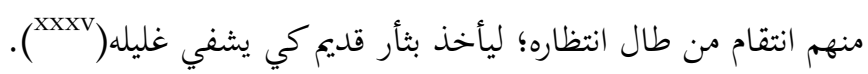
المثال الثاني:

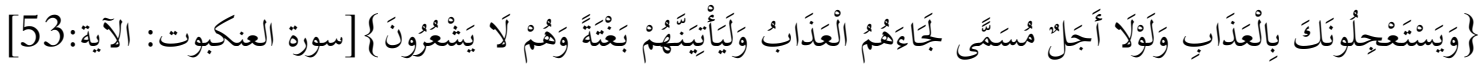
فالعذاب هو العقوبة والجزاء السيء الذي يلاقيه أهل النار، وهو معنوي في الأصل، غيبي مشخص مجسد وكأنه وحش يأتي

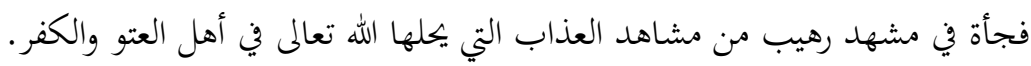

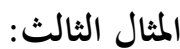

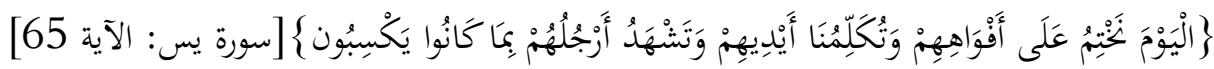

وهكذا يخذل بعضهم بعضاً، وتشهد عليهم جوارحهم، وتنفكك شخصيتهم مزقاً وآحاداً يكذب بعضها بعضاً. وتعود كل

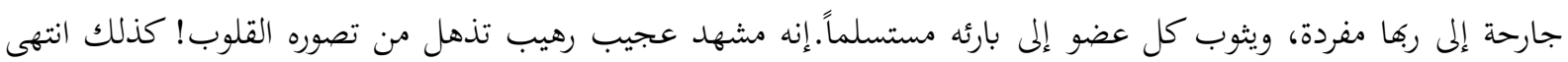

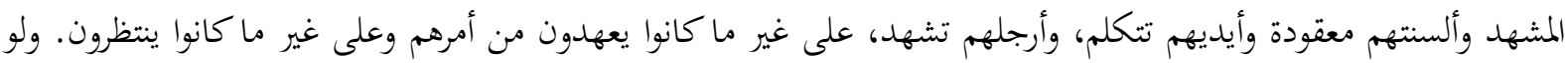
شاء الله لفعل بهم غير ذلك، ولأجرى عليهم من البلاء ما يريد( 


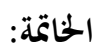

من خلال ما تقدم نستخلص الآتي:

1. يجب أن يدرس القرآن دراسة مورية شاملة لا متجزئة كل آية على حدة.

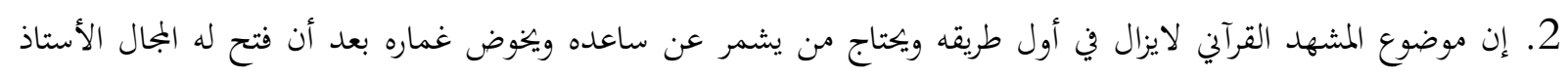

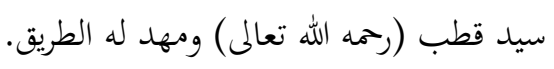


أسرار البلاغة، أبو بكر عبد القاهر بن عبد الرمن بن محمد الفارسي الأصل، الجرجاني الدار (ت: 471 هـ)،رأه وعلق عليه:

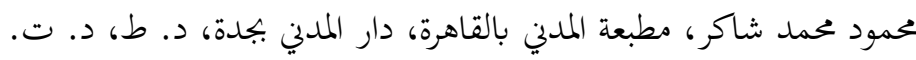

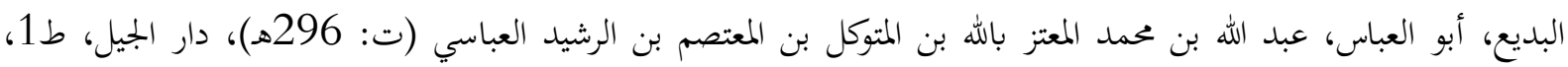

$$
\text { 1410هـ - 1990م. }
$$

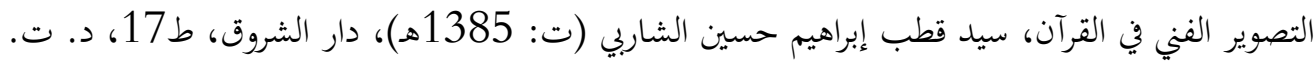

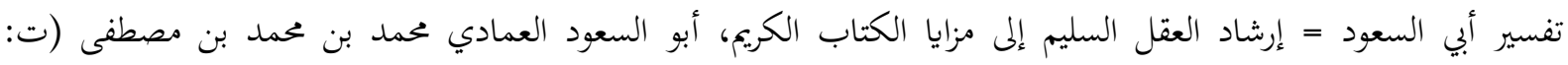

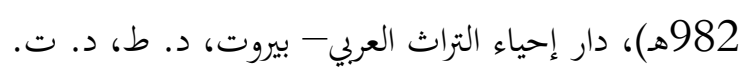

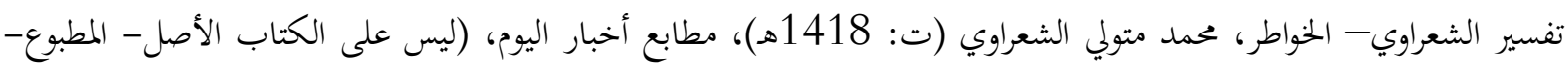

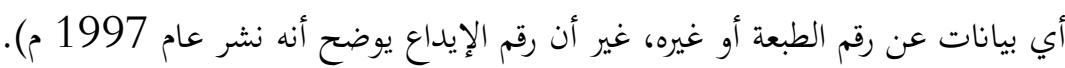

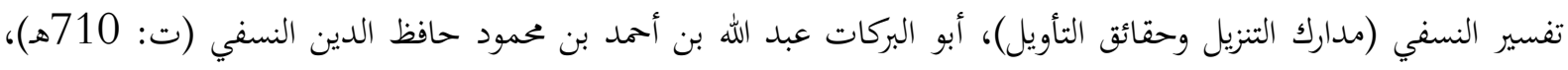

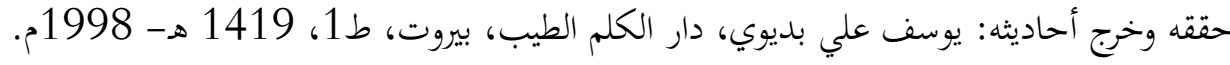

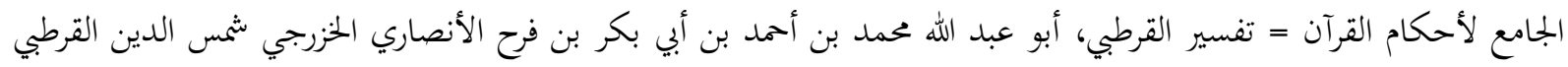

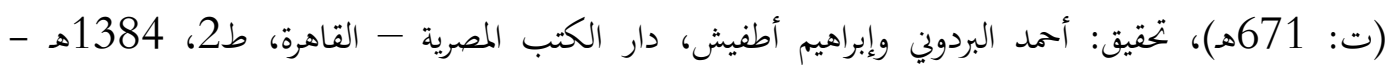

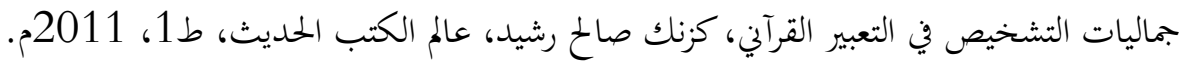

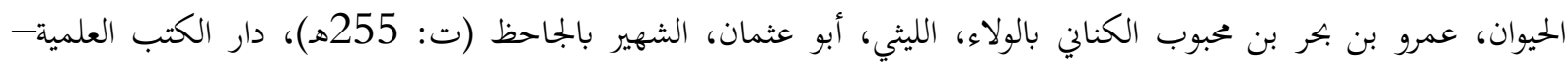

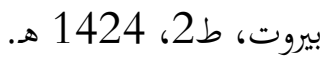

ديوان امرئ القيس، اعتنى به: عبد الرمن المصطاوي، دار المعرفة- بيروت، ط2، 1425، 1425هـ- 2004م.

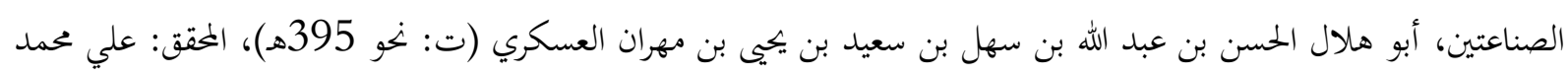

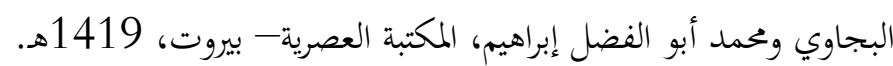

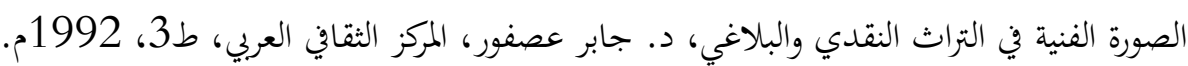

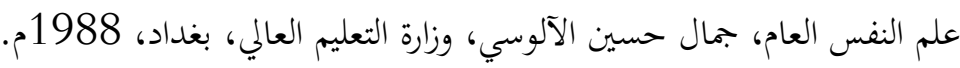

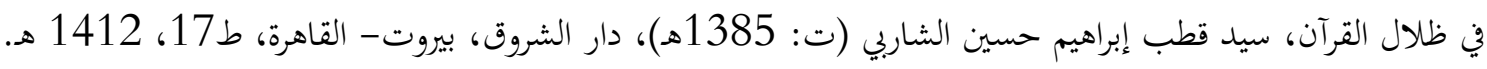

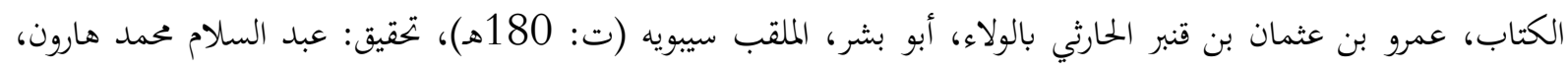

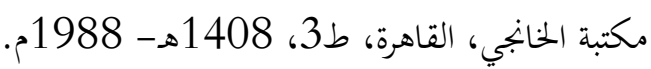

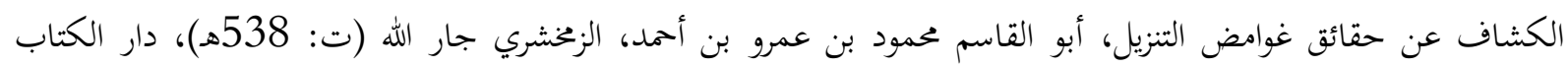

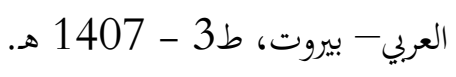

لسان العرب، عمد بن مكرم بن على، أبو الفضل، جمال الدين ابن منظور الأنصاري الرويفعى الإفريقى (ت: 714 هـأه)، دار

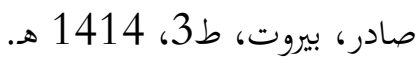

مجاز القرآن، أبو عبيدة معمر بن المثنى التيمى البصري (ت: 209 2013ه)، تحقيق: محمد فواد سزّين، مكتبة الخانجى- القاهرة، طبعة 1381

المعجم الوسيط، مجمع اللغة العربية بالقاهرة، (إبراهيم مصطفى / أحمد الزيات / حامد عبد القادر / عحمد النجار)، دار الدعوة

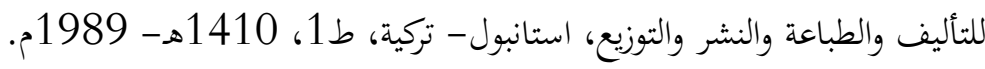


معجم مقاييس اللغة، أحمد بن فارس بن زكرياء القزويني الرازي، أبو الحسين (ت: 395هـ)، تحقيق: عبد السلام محمد هارون، دار

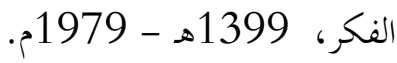

من بلاغة القرآن، أحمد أحمد عبد الله البيلي البدوي (ت: 1384هـ)، غضضة مصر- القاهرة، 2005م.

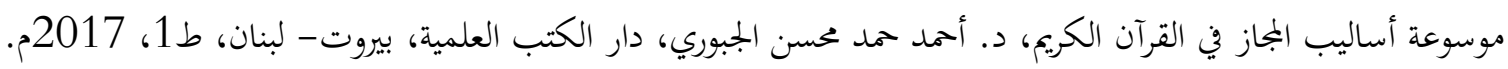


أمعجم مقاييس اللغة, أحمد بن فارس بن زكرياء القزويني الرازي، أبو الحسين (ت: 395ه)، تحقيق: عبد السلام محمد هارون, دار الفكر , 1399هـ - 1979م:

iii لسان العرب, محمد بن مكرم بن على، أبو الفضل، جمال الدين ابن منظور الأنصاري الرويفعى الإفريقى (ت: 711هـ), دار صادر، بيروت, ط3، 1414 هـ:

$.338 / 3$

iii المعجم الوسيط, مجمع اللغة العربية بالقاهرة (إبراهيم مصطفى / أحمد الزيات / حامد عبد القادر / محمد النجار), دار الدعوة للتأليف والطباعة والنشر والتوزيع, (14)

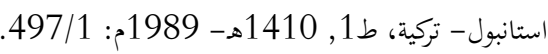
iv التصوير الفني في القرآن, سيد قطب إبراهيم حسين الشاري (ت:

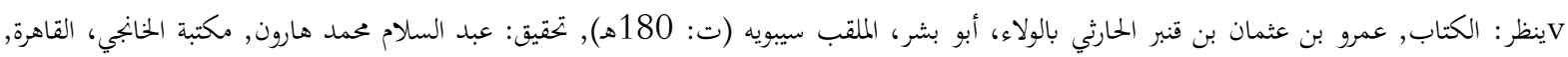
ط3، 1408 هـ 1408 هـ 1988م: 193

Vi vجاز القرآن, أبو عبيدة معمر بن المثنى التيمى البصري (ت: 209هـ), تحقيق: محمد فؤاد سزگين، مكتبة الخنانجى- القاهرة, طبعة 1381 هـ: 1 / 10.

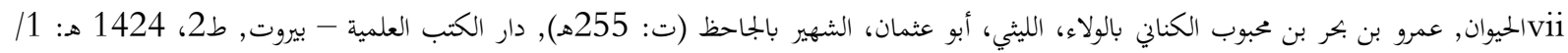

viii ديوان امرِئ القيس, اعتنى به: عبد الرحمن المصطاوي, دار المعرفة- بيروت, ط2، 1425هـ- 2004م: 15.

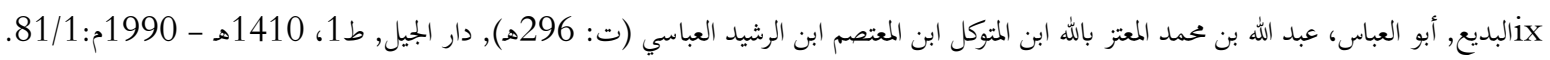

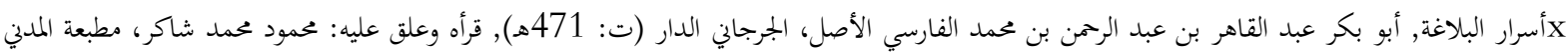

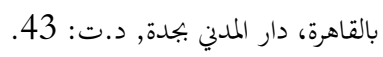
46-45:xi

Xنصوير الفني في القران: 33-Xii

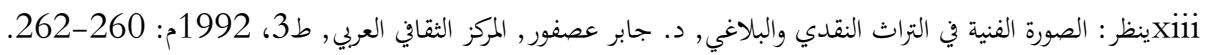

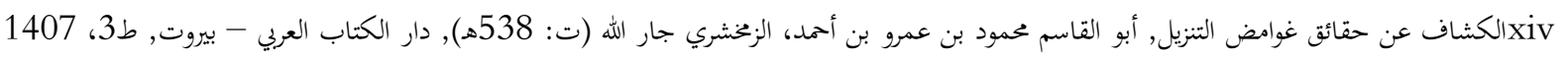
397/2 هـ

Xي ظلال القرآن, سيد قطب إبراهيم حسين الشاربي (ت: 1385هـ), دار الشروق، بيروت- القاهرة, ط17، 1412 هـ: 14 / 1879.

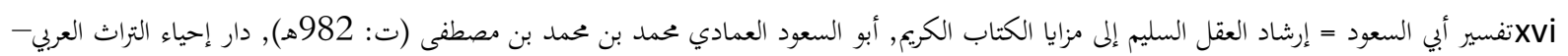

بيروت, د. ط, د. ت: 211/4

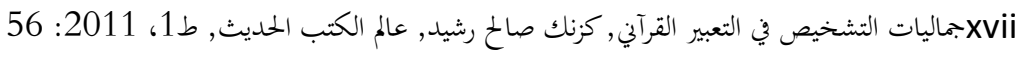

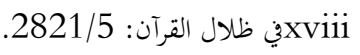

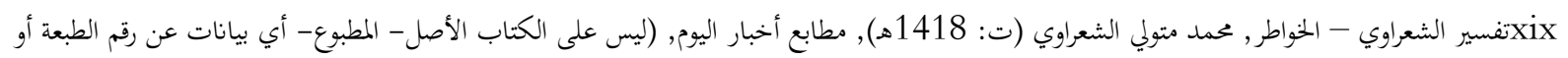

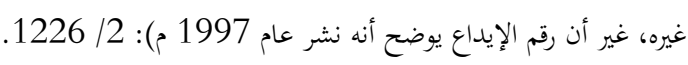
في ظلال القرآن:5xx جماليات التشخيص في التعبير القرآي: 76 فxxi علم النفس العام, جمال حسين الآلوسي, وزارة التعليم العالي, بغداد، فئسئ 1988xii في ظاعلال القران:xxiii الكشاف:16xiv XXV الصناعتين, أبو هلال الحسن بن عبد الله بن سهل بن سعيد بن يميى بن مهران العسكري (ت: نحو 395هـ), تحقيق: علي محمد البجاوي ومحمد أبو الفضل

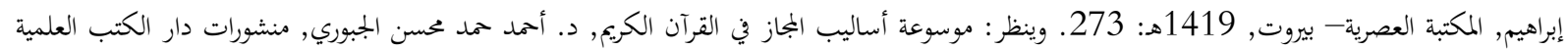
بيروت- لبنان, ط1، 2017م: 328.

xixxvi

تفسير أبي السعود:117xxvii Xi في ظلال القرآن: 38xviii تفسير النسفي (مدارك التنزيل وحقائق التأويل), أبو البركات عبد الله بن أحمد بن محمود حافظ الدين النسفي (ت: 710هix

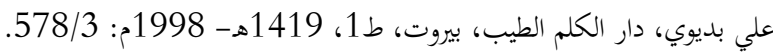

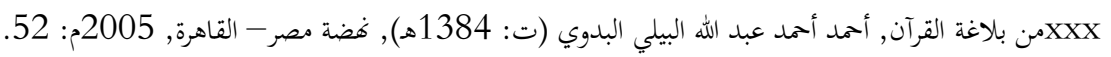


جمxxi لسان العرب, محمد بن مكرم بن على، أبو الفضل، جمال الدين ابن منظور الأنصاري الرويفعى الإفريقى (ت: 711 7هات), دار صادر، بيروت, ط3، 1414 هـ: مادة (ب) xiluxxiii

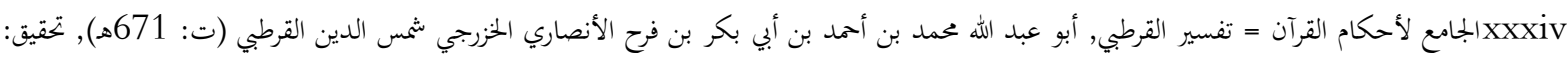

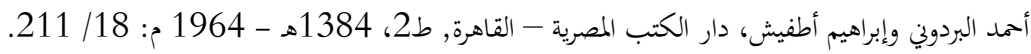
Xمxxv ماليات التشخيص في التعبير القرآني: 162. xفxxvi 